\title{
Assessment of grain losses during harvesting of grain crops on the basis of technical and economic indicators
}

\author{
Igor Khozyaev ${ }^{1}$, Vyacheslav Ladyanov ${ }^{1}$, Larisa Enalyeva ${ }^{1}$, Maria Balinskaya ${ }^{1, *}$, Viktor \\ Zharov $^{1}$ \\ ${ }^{1}$ Don State Technical University, Gagarina square 1, Rostov-on-Don, 344003, Russia
}

\begin{abstract}
The article presents a method for determining the optimal losses of grain during combine harvesting (direct and with the selection of rolls). Based on the quoted operating costs. It is shown that there is no need to limit the losses from mechanical damage to the grain. But their level should not exceed $2.2 \%$. Under these conditions, the cleaning period should be no more than 14 days and there will be a reduction in the reduced costs by $0.3 \%$.
\end{abstract}

\section{Introduction}

The gross harvest of grain crops in Russia is constantly increasing and in 2018 amounted to 114 million tons [1]. The question is, how much grain was lost. And on this basis to determine possible ways to reduce losses.

During harvesting there are biological and mechanical losses.

Biological losses depend on the time of stagnation of bread. Pugachev A. N. studies [ 2 ] determined the levels of grain losses of different crops depending on the days of stagnation. The data of these studies, plotted on a logarithmic probability grid, fall on a straight line (Fig. 1), which indicates the applicability of the Laplace function for the analytical description of the grain loss law: [ 3 ]

$$
\Pi(\mathrm{D})=\phi(\mathrm{X})+0,5,
$$

where П (D) -integral function of grain losses (in fractions);

$\phi(\mathrm{X})$ - Laplace function;

$\mathrm{X}=(\ln \mathrm{D}-\ln \neg D) / \sigma$;

$\neg D$ - the period of stagnation corresponding to $50 \%$ of grain losses.

\footnotetext{
*Corresponding author: mbalinskaya91@gmail.com
} 


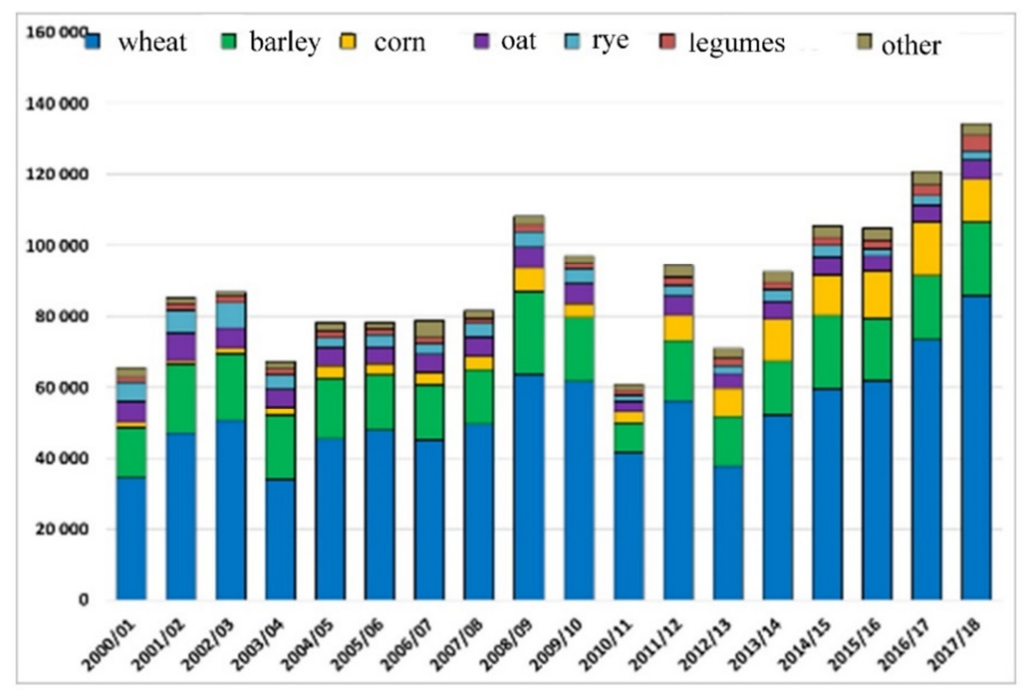

Fig. 1. Gross grain harvest in Russia $2000-2018$

\section{Materials and Methods}

Since the values are distributed over the entire interval from 0 to 1 , you can accept $3 \sigma=\ln \neg D$

$$
\text { Then } X=\frac{3}{\ln \neg D} \cdot \ln \frac{D}{\neg D},
$$

From the chart it will be determined that $\mathrm{D} \approx 50$ days.

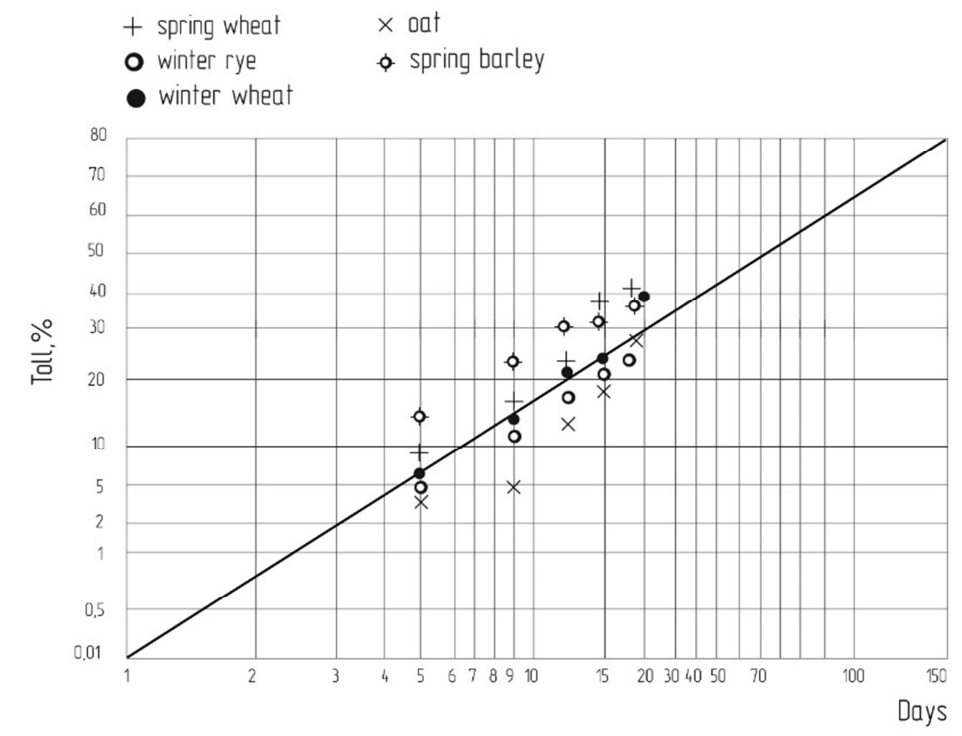

Fig. 2. Dependence of grain losses on the duration of interruption 


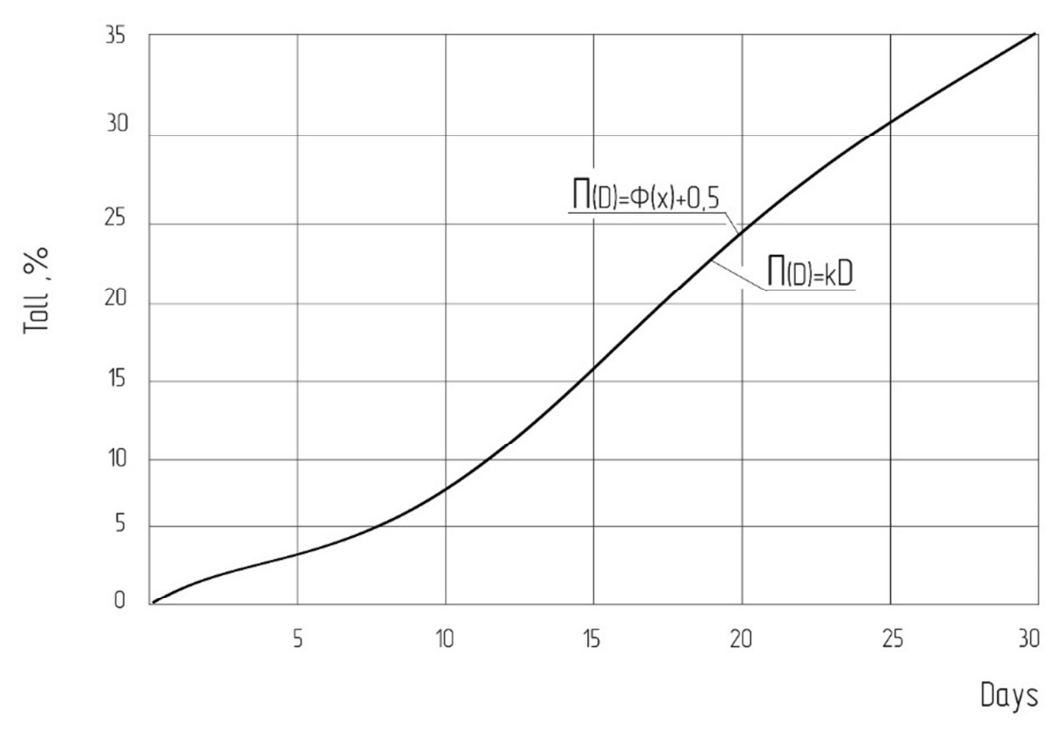

Fig. 3. Grain loss function in linear coordinates

Representation of the function N (D) in linear coordinates (Fig. 3), indicates that in the interval of 10 to 30 days of stagnation, it can be replaced by a linear function

$$
\Pi=\mathrm{kD} \text {, }
$$

where $\mathrm{k}=0,012$ - average daily losses for 1 day of stoppage

The value of losses for each day of stoppage is equal to:

$$
\Delta \Pi(D)=\phi\left(\frac{3}{\ln \neg D} \cdot \ln \frac{D+1}{\neg D}\right)-\phi\left(\frac{3}{\ln \neg D} \cdot \ln \frac{D}{\neg D}\right)
$$

or in another form:

$$
\Delta \Pi(D)=\ln \frac{D+1}{D} \cdot \frac{3}{\ln \neg D} \cdot \frac{1}{2 \pi} \exp \left(-0,5 \cdot\left(\frac{3}{\ln \neg D} \ln \frac{D}{\neg D}\right)^{2},\right.
$$

In the process of harvesting, the area of fields where grain is shedding decreases and on the first day of harvesting is

$$
\mathrm{F}_{\mathrm{i}}=\mathrm{F}\left(1-\mathrm{D}_{\mathrm{i}} / \mathrm{D}_{\mathrm{y}}\right)
$$

where $\mathrm{F}$ - is the total area of the field;

Dy -the number of days to harvest;

Grain losses (in fractions of $\%$ ) occurring on the first day of harvesting per 1 hectare of the field will be:

$$
\Pi_{\Sigma}(D)=\sum_{i=1}^{D}\left(1-\frac{D}{D_{y}}\right) \Delta \Pi(D)
$$

The calculations performed for different cleaning times according to this equation are illustrated by the graph in Fig. 4, indicate that the total losses for the harvesting period of more than 6 days can be approximated by the equation

$$
\Pi_{\Sigma}(\mathrm{D})=\gamma\left(\mathrm{D}_{\mathrm{y}}-\mathrm{D}_{\mathrm{o}}\right)
$$


where $\gamma=0,0064, \mathrm{D}_{\mathrm{o}}=3$.

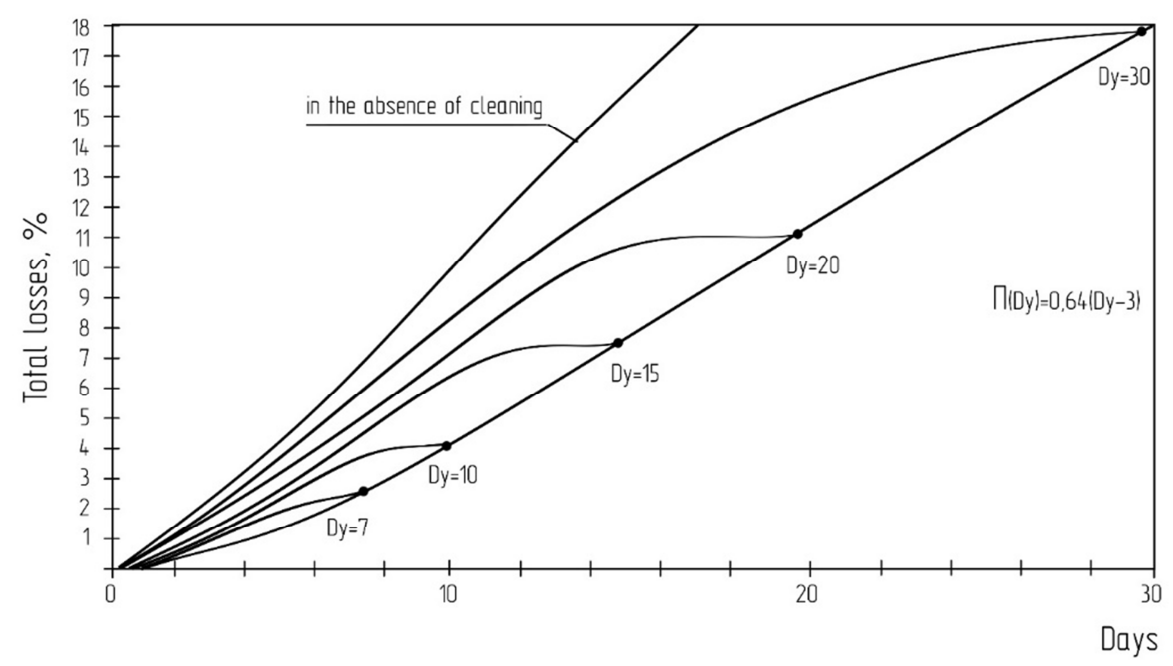

Fig. 4. Dynamics of grain losses at different harvesting periods

The costs of cleaning fields with area $F$ and yield $U$ are the sum of operating costs, capital investments, the cost of mechanical losses of grain during harvesting and biological losses: [ 4 ]

$$
\mathrm{C}=(\mathrm{I}+\mathrm{kE}) \mathrm{FU}_{2}+\alpha_{2} \mathrm{FU}_{1} \mathrm{U}_{13}+\gamma\left(\mathrm{D}-\mathrm{D}_{\mathrm{o}}\right) \mathrm{FU} \mathrm{U}_{13},
$$

where I - direct operating costs per unit of operating time, RUB;

$\mathrm{k}$-capital investments per unit of operating time, RUB.;

$\alpha$-share of mechanical losses during cleaning;

$\mathrm{D}$ - number of calendar days of cleaning;

$\mathrm{U}_{13}-$ cost of 1 ton of grain, RUB/ t;

$\mathrm{U}_{1=} \mathrm{U} \cdot\left(1-\gamma\left(\mathrm{D}-\mathrm{D}_{\mathrm{o}}\right)\right)-$ yield of the field at the time of harvesting, $\mathrm{t} / \mathrm{ha}$;

$\mathrm{U}_{2}=\mathrm{U} \cdot\left(1-\gamma\left(\mathrm{D}-\mathrm{D}_{\mathrm{o}}\right)\right)$ - the yield of the fields on the collected seed.

The cost per 1 ton of harvested grain is determined by dividing all terms of equation (8) by the product $\mathrm{F} \cdot \mathrm{U} 2$ :

$$
\Pi=(I+\mathrm{KE})+\frac{\propto C_{3}}{1-\alpha}+\frac{C_{3} \gamma\left(D-D_{0}\right)}{(1-\alpha)\left(1-\gamma\left(D-D_{0}\right)\right)}
$$

Substituting the values of direct operating and capital costs into the formula, we obtain the dependence of the reduced costs for cleaning, taking into account the losses of grain:

$$
\Pi=\left(Z+G+\frac{\left[\sum C_{i}\left(a_{i}+E\right) / K_{3 i}\right] \cdot m \cdot O_{c}}{W_{\ni \mathrm{K}} \cdot T_{\mathrm{CM}} \cdot D \cdot K_{a}}+\frac{m}{W_{\ni \mathrm{K}}}+\sum \frac{C_{i} \cdot r_{i}}{T_{i}}\right)+\frac{\mathrm{C}}{1-\propto}\left(\frac{1}{\frac{1}{\mathrm{\gamma}\left(D-D_{0}\right)}-1}+\propto\right),
$$

where Z - salary, RUB / t;

$\mathrm{G}$ - fuel costs, RUB / t;

$\mathrm{m}$-conversion factor of wholesale price to balance;

$\mathrm{U}_{\mathrm{i}}-$ the price of the I-th machine, RUB.; 
$\mathrm{W}_{\text {эк }}$-productivity per hour of operating time, $\mathrm{t} / \mathrm{h}$;

$r_{i}-$ coefficient of deductions for the repair of the I-th machine;

$\mathrm{a}_{\mathrm{i}}$ - coefficient of deductions for the renovation of the I-th machine;

$\mathrm{E}$ - coefficient of normative deductions;

$\mathrm{K}_{\mathrm{a}}$ - utilization agrorama (the ratio of working days per period harvest calendar);

$\mathrm{T}_{\mathrm{cm}}-$ shift time, hour;

$\mathrm{T}_{\text {норм і }}$ - normalized annual load of the I-th machine, hour;

$\mathrm{O}_{\mathrm{c}}$ - at the same time, the share of Mature fields;

$\mathrm{K}_{3 \mathrm{i}}=1+\sum F \mathrm{~K} F \cdot \mathrm{Oc}-$ load factor of the $\mathrm{i}-$ th machine taking into account other crops;

$\sum \mathrm{F}_{\mathrm{K}}$ - the area of fields occupied by other crops.

The minimum cost for the cleaning is ensured by the condition $\mathrm{d} \Pi / \mathrm{dD}=0$,

$$
-\frac{m \cdot o_{c}}{W_{\Im \mathrm{K}} T_{\mathrm{CM}} K_{a} D^{2}} \sum \frac{C_{i}\left(a_{i}+E\right)}{K_{3 i}}+\frac{\mathrm{C \gamma}}{\left.2(1-\gamma)\left(D-D_{0}\right)\right)^{2}}=0
$$

where is the optimal number of calendar days of cleaning determined:

$$
D=\left(1+\gamma D_{0}\right) /\left[\gamma+\sqrt{\frac{W_{3} K_{a} T_{\mathrm{cM}} \gamma C_{3}}{(1-\alpha) \cdot O_{c} \cdot m} \sum \frac{K_{3 i}}{C_{i}\left(a_{i}+E\right)}},\right.
$$

According to formula 12, the values of optimal harvesting times can be determined during direct combine harvesting and when mowing bread into rolls. From the analysis of the formula it follows that the optimal duration of harvesting depends on the ratio of prices for harvesting equipment and grain, as well as on the value of the coefficient of use of agricultural machinery. The cost of cleaning the fields separately is determined by the expression:

$$
\begin{aligned}
& \mathrm{C}=(\mathrm{I}+\kappa \cdot \mathrm{E}) \cdot \mathrm{FU}_{4}+\alpha_{1} \mathrm{FU}_{3} \mathrm{C}_{3}+\gamma_{\mathrm{n}}\left(\mathrm{D}_{1}+\left(\mathrm{D}_{\mathrm{n}}-\mathrm{D}_{\mathrm{ck}}\right) / 2\right) \mathrm{FU}_{2} \mathrm{C}_{3}+\left(\frac{\mathrm{P} 1}{\mathrm{L3}}+\alpha\right) \mathrm{FU}_{1} \mathrm{C}_{3}+\gamma\left(\mathrm{D}_{\mathrm{ck}^{-}}\right. \\
& \left.\quad \mathrm{D}_{0}\right) \mathrm{FUC}_{3},
\end{aligned}
$$

where $\mathrm{U}_{1}=\mathrm{U}\left(1-\gamma\left(\mathrm{D}_{\mathrm{ck}}-\mathrm{D}_{0}\right)\right)-$ yield at the time of mowing, $\mathrm{t} /$ ha;

$\mathrm{U}_{2}=\mathrm{U}_{1}(1-\alpha)-$ the yield after grazing, $\mathrm{t} / \mathrm{ha}$;

$\mathrm{U}_{3}=\mathrm{U}_{2}(1-\gamma \mathrm{n}(\mathrm{D} 1+(\mathrm{Dn}-\mathrm{Dc \kappa}) / 2))$ - productivity before selection of rolls, $\mathrm{t} /$ ha;

$\mathrm{U}_{4}=\mathrm{U}_{3}\left(1-\alpha_{1}\right)$ - yield of harvested grain, $\mathrm{t} / \mathrm{ha}$;

$\gamma_{\mathrm{n}}=0,45 \kappa / \kappa-$ the daily loss from shedding in the rolls, taking into account climatic conditions of the zones;

$\mathrm{k}=0,012$ - average daily losses from grain shedding during the days of stagnation;

$\mathrm{P}_{1}$ - reduced costs for mowing, RUB / $\mathrm{t}$;

$\mathrm{D}_{1}-$ minimum roll drying time, days;

$\alpha_{1}-$ mechanical losses in the selection of rolls;

$\mathrm{D}_{\mathrm{cK}}-$ duration of fermentation, days;

$\mathrm{D}_{\mathrm{n}}-$ the duration of the selection of rolls days.

The solution of this equation is carried out similarly to the solution of equation (8), under the condition $\mathrm{d} N / \mathrm{d}=0$, the optimal period of selection of rolls is determined:

$$
D=\left(1+\gamma D_{0}\right) /\left[\gamma+\sqrt{\frac{W_{9} K_{a} T_{\mathrm{cM}} \gamma C_{3}}{(1-\alpha) \cdot O_{c} \cdot m} \sum \frac{K_{3 i}}{C_{i}\left(a_{i}+E\right)}},\right.
$$

Total grain losses in direct combination can be calculated by the formula

$$
\mathrm{P}=\gamma\left(\mathrm{D}-\mathrm{D}_{0}\right)+\alpha
$$

And at separate cleaning according to the formula 


$$
\mathrm{P}=\gamma\left(\mathrm{D}_{\mathrm{c \kappa}}-\mathrm{D}_{0}\right)+\gamma_{\mathrm{n}}\left(\mathrm{D}_{1}-\mathrm{D}_{\mathrm{c \kappa}} / 2\right)+\alpha+\alpha_{1}
$$

The increase in the productivity of the combine is accompanied by an increase in the proportion of mechanical losses (Fig. 5) [5,6]. The relationship of the level of losses with the productivity of the harvester can be determined by the dependence:

$$
\mathrm{W}=\mathrm{WH}\left(1+f \ln \frac{\alpha}{\alpha \mathrm{n}}\right),
$$

where W - nominal productivity of the combine determined at the level of mechanical losses $\alpha \mathrm{n}=1,5 \%$;

$f$ - the coefficient for harvesters family of $\langle$ Don $»=0,5$.

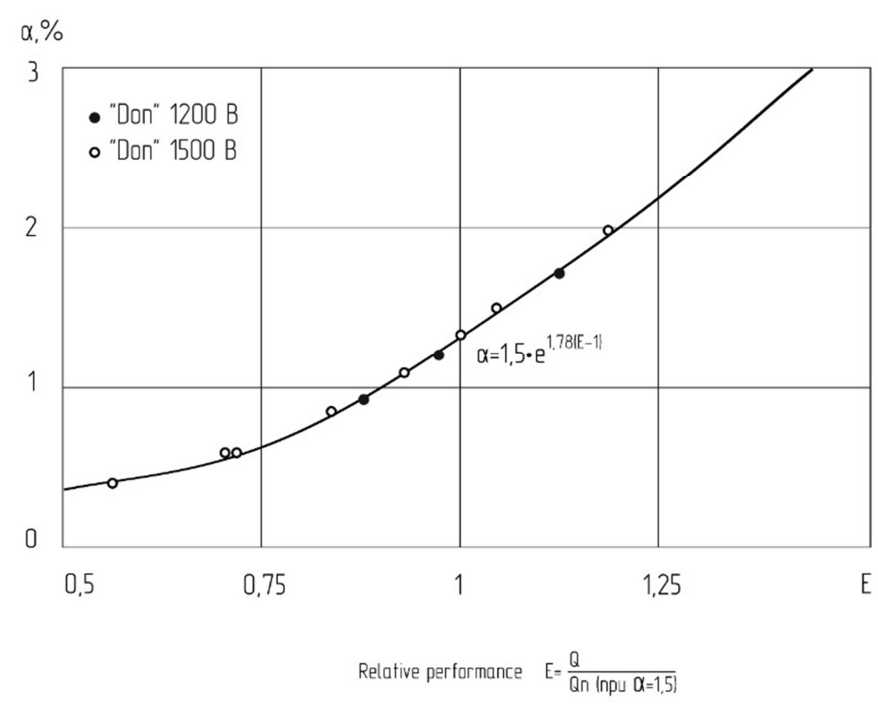

Fig. 5. The dependence of mechanical losses on the performance of the combine of the Don family (RSM 142 Across)

Increasing the normative level of mechanical losses an allows to increase productivity, reduce the optimal harvesting time and thereby reduce the biological loss of grain from stagnation.

Increasing the productivity of harvesters will reduce their fleet:

$$
\Pi_{\mathrm{K}}=\Pi_{\mathrm{KH}} \cdot \frac{D_{\mathrm{H}} \cdot W_{\mathrm{H}}}{D \cdot W},
$$

where $\mathrm{P}_{\mathrm{kn}}$ - combine harvester fleet at the normative term cleaning of the Bottom with the productivity of the Bottom;

$\mathrm{P}_{\mathrm{k}}$ - park harvesters at optimal harvesting time D with Windows performance.

Results of calculations of total losses of grain (at direct combining), illustrated by the graph in Fig.6, indicate the dependence of total losses on the level of permissible mechanical losses and cleaning time. 


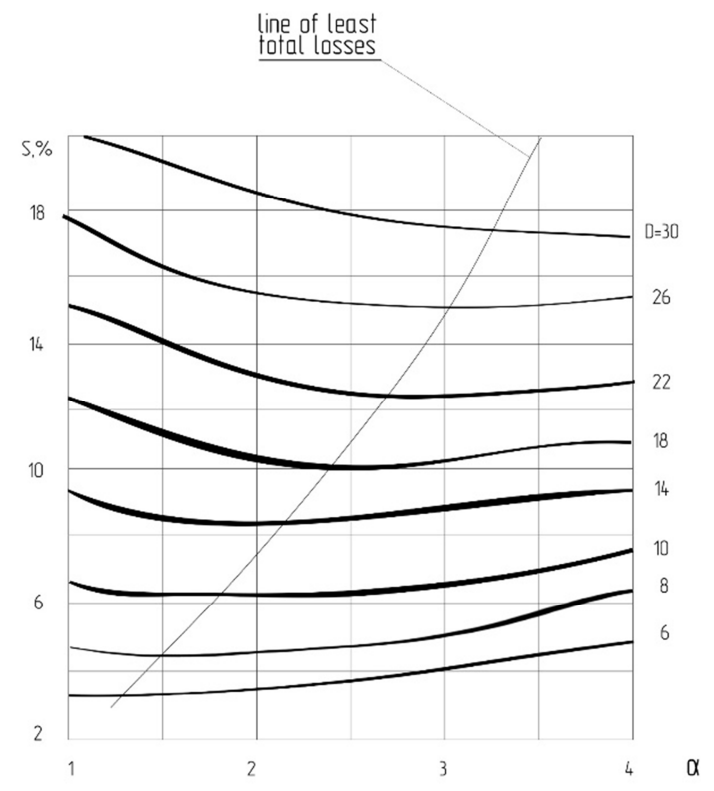

Fig. 6. The dependence of the total grain loss (S,\%) on the level of mechanical loss $\alpha$ and harvesting time D

For rice.7 the graph of dependence of admissible mechanical losses on duration of cleaning at which the lowest level of total losses of grain is provided is presented. It follows from the graph that the value of permissible mechanical losses during cleaning is not a constant value.

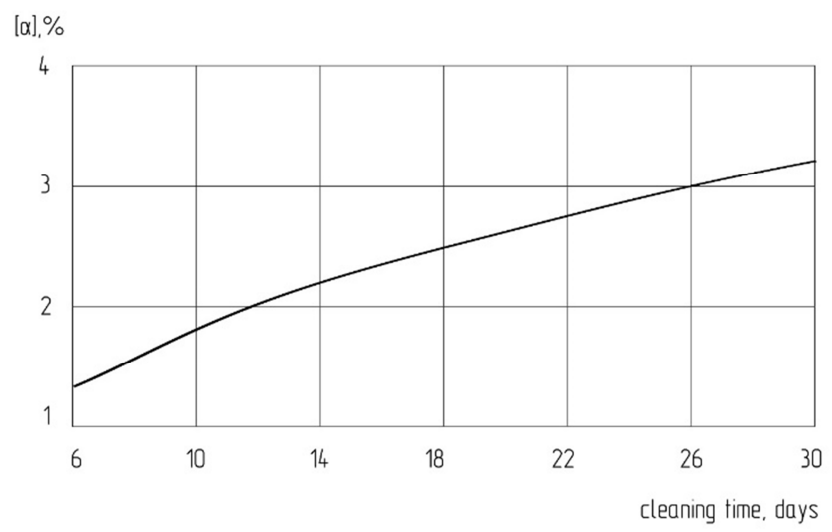

Figure 7. The dependence of the permissible level of mechanical losses of grain from the harvesting period

\section{Conclusion}


1. The developed technique of determination of terms of combine harvesting of grain crops on the basis of technical and economic indicators of their work.

2. Regulation of mechanical losses in technical documentation is not obligatory, and the choice of their sizes is defined by productivity and duration of cleaning which, in turn, is defined by level of the developed prices for grain and equipment.

At the moment the optimal cleaning time of the combine harvester "don 1500B" is 14 days, and the permissible level of mechanical losses is within $2.2 \%$. At the same time, the total losses during cleaning will amount to $7.7 \%$, instead of $8 \%$.

\section{References}

1. Federal State Statistics Service. Russian statistical yearbook, 374 (2018)

2. A.N. Pugachev, Quality control of grain harvesting, 58 (1980)

3. N.G. Taktarov, Handbook of higher mathematics for university students. Librocom, 447 (2018)

4. OST R 54784 - 2011. Tests of agricultural machinery. Methods for evaluating technical parameters dated 12/27/2002 No. 184: introduction date 2012 - 03-01. URL: http://docs.cntd.ru/document/1200089620 (accessed date: 11.11.2019)

5. G.A. Filenko, Grain losses during the harvesting of winter wheat (review) Grain farming in Russia, 1, 28-32 (2018)

6. N.N. Stepanov, Comparative analysis of the work of combine harvesters. Bulletin of the Irkutsk State Agricultural Academy, 81, 133-138 (2017)

7. A.I. Buryanov, Results of researches on determination of influence of duration of carrying out cleaning on size of biological losses of grain. Technics and the equipment for the village, 11, 11-14 (2015)

8. R.I. Ibragimov, Losses at cleaning. Scientific and educational potential of youth in the solution of actual problems of the XXI century, 7, 180-182 (2017)

9. V.S. Pyanov, V.V. Tsybulevsky, SH. N. Bogus, SVID. No2014618442 Russian Federation of 20.09.2014. Calculation of the daily gross harvest of grain in the economy depending on the rate of harvesting and their duration, declared.01.07.2014, registered 20.08.2014

10. GOST 28301-2007. Combine harvesters. Test methods of 24.10.2007 No. 32: date of introduction 2010-01-01. URL: http://docs.cntd.ru/document/gost-28301-2007 (accessed 12.11.2019)

11. R.I. Ibrogimov, Grain Losses during harvesting. Scientific and educational potential of youth in solving urgent problems of the XXI century, 7, 180-182 (2017) 